\title{
NiTi Endodontics: Contemporary Views Reviewed
}

\author{
Agarwal S, Nagpal $\mathbf{R}^{*}$ and Singh UP \\ Department of Conservative Dentistry and Endodontics, \\ Kothiwal Dental College and Reasearch Centre, India \\ *Corresponding author: Nagpal R, Department of \\ Conservative Dentistry and Endodontics, Kothiwal Dental \\ College and Research Centre, Moradabad, Uttar Pradesh \\ 244001, India
}

Received: J anuary 23, 2018; Accepted: February 26 , 2018; Published: March 28, 2018

\section{Abstract}

$\mathrm{NiTi}$ endodontic instruments have gained extensive popularity due to their superelasticity and greater torsional resistance than the traditional stainlesssteel files. Therefore, various $\mathrm{NiTi}$ endodontic files with thermomechanical processing such as M-wire, controlled memory, and R-phase with different kinematics and design features have been introduced to show improved flexibility and cyclic fatigue resistance compared to the traditional superelastic $\mathrm{NiTi}$ files. The knowledge of the mechanical properties and their association with the metallurgical properties or kinematics of $\mathrm{NiTi}$ rotary instruments is helpful to understand the behaviour of NiTi instruments in root canals and to make decisions regarding which instruments are appropriate for root canal therapy. Therefore, this review discusses the microstructure, thermomechanical treatments, design features, mechanical properties and kinematics of the traditional and contemporary NiTi instruments and the influence of these factors on their clinical performance.

Keywords: NiTi endodontics; Microstructure and phases; Design features; Reciprocation; Glidepath

\section{Introduction}

Nickel-titanium alloy was introduced in endodontics 30 years ago when Walia, et al. [1] employed a nickel-titanium arch wire to fabricate a root canal file in 1988. NiTi endodontic instruments have gained extensive popularity due to their superelasticity and greater torsional resistance than the traditional stainless-steel files $[1,2]$. Therefore, various NiTi endodontic files with different geometric designs have been developed [3-5]. However, the unexpected separation of NiTi endodontic rotary files during root canal instrumentation still remains a serious drawback in clinical use. Recently, novel kinds of NiTi endodontic files fabricated by proprietary thermomechanical processes such as M-wire files, controlled memory (CM) files, and $\mathrm{R}$-phase wire with different kinematics and design features have been introduced showing improved flexibility and cyclic fatigue resistance compared to the traditional superelastic NiTi files [6-10].

The knowledge of the mechanical properties and their association with the metallurgical properties or kinematics of NiTi rotary instruments is helpful to understand the behavior of NiTi instruments in root canals and to make decisions regarding which instruments are appropriate for root canal therapy. Therefore, this review is intended to summarize the design features and mechanical properties of the traditional superelastic NiTi instruments and contemporary NiTi instruments, and to provide a comparative assessment of rotary and reciprocating motion, discuss the importance of glide path as well as the influence of metallurgical properties on the mechanical properties of NiTi instruments, with a special focus on factors affecting the success of rotary endodontics.

\section{NiTi: metallurgical structure and phases}

The mechanical behavior of NiTi alloy is determined by the relative proportions and characteristics of the microstructural phases [11]. Heat treatment (thermal processing) is one of the most fundamental approaches toward adjusting the transition temperatures of $\mathrm{NiTi}$ alloys [12-14] and affecting the fatigue resistance of NiTi endodontic files.

NiTi alloys with nearly equiatomic ratio possess the unique superelasticity and shape memory effect [15]. That is why the NiTi alloys used in root canal treatment contain approximately $56 \%$ (wt) nickel and $44 \%$ (wt) titanium (1) resulting in a 1:1 atomic ratio (equiatomic) of the major components. NiTi can have 3 different forms: martensite, austenite, and R-phase, the character and relative proportions of which determine the mechanical properties of the metal [16]

\section{Austenitic and martensitic phases}

The crystal structure of NiTi alloy at high temperature ranges $\left(100{ }^{\circ} \mathrm{C}\right)$ is a stable, Body-Centred Cubic (bcc) lattice which is referred to as the austenite phase or parent phase. NiTi when cooled through a critical transformation temperature range (TTR), shows a change in the crystal structure known as the martensitic transformation, with changes in its modulus of elasticity (stiffness), yield strength and electric resistivity giving rise to the shape memory characteristic [11].

The martensite phase is a low-temperature phase with monoclinic structure $\left(\mathrm{B} 19^{\prime}\right)$, possessing a relatively lower Young's modulus (20$50 \mathrm{GPa}$ ) and yield strength (138 GPa) than the austenite (40-90 GPa and $379 \mathrm{GPa}$, respectively) [17-19].

The transformation induced in the alloy may also occur by a shear type of process the martensitic or daughter phase, which gives rise to twinned martensite forming the structure of a closely packed hexagonal lattice. Almost no macroscopic shape change is detectable on the transformation, unless there is application of an external force. The martensite shape can be deformed easily to a single orientation to the de-twinned martensite when there is a 'flipping over' type of shear [2]. The NiTi alloy is more ductile in the martensitic phase than the austenite phase.

Martensitic phase has remarkable fatigue resistance and they can
Austin J Dent - Volume 5 Issue 4 - 2018

ISSN : 2381-9189 | www.austinpublishing group.com

Nagpal et al. () All rights are reserved
Citation: Agarwal S, Nagpal R and Singh UP. NiTi Endodontics: Contemporary Views Reviewed. Austin J Dent. 2018; 5(4): 1112 
easily be deformed [20]. The deformation can be reversed by heating the alloy above the TTR. The alloy resumes the original parent structure with a stable energy condition. The temperature at which this phenomenon begins is called the austenite transformation start temperature (As). The temperature at which this phenomenon is completed is called the austenite finish temperature (Af).

The transition from the austensitic to martensitic phase also occurring as a result of application of stress as during root canal preparation is referred to as stress-induced martensitic transformation.

When the material is in its martensite form, it is soft and ductile and can easily be deformed. Besides being more flexible than austenite, the martensite favours reducing the risk of file fracture under high stress because it can be plastically deformed rather than broken.

\section{Thermomechanical Heat Treatment Novel/Contemporary NiTi Instruments \\ M wire}

It is a modification of the super-elastic $508 \mathrm{NiTi}$ alloy used for endodontic instruments developed [21] by Dentsply. M-Wire, introduced in 2007 , is produced by applying a series of heat treatments to NiTi wire blanks. Johnson, et al. [22] reported that instruments made from M-Wire with a ProFile design exhibited nearly $400 \%$ more resistance to cyclic fatigue than super-elastic wire instruments of the same size. Instruments with $\mathrm{M}$-with technology include ProTaper Next, Profile Vortex, WaveOne and Reciproc.

\section{CM wire}

CM Wire is a novel NiTi alloy with flexible properties that was introduced in 2010. CM NiTi files have been manufactured using a special thermomechanical process that controls the memory of the material, making the files extremely flexible but without the shape memory of other NiTi files, as opposed to what is found with conventional super-elastic forms of $\mathrm{NiTi}$ [23]. Instruments made from CM Wire are nearly $300 \%-800 \%$ more resistant to fatigue failure than instruments made from conventional NiTi wire [8].

CM Wire and M-Wire instruments have increased austenite transformation temperatures. The Af of CM Wire, M-Wire, twisted file, and conventional super-elastic NiTi wire are approximately $55^{\circ} \mathrm{C}$, $50^{\circ} \mathrm{C}, 17^{\circ} \mathrm{C}$, and $16^{\circ} \mathrm{C}-31^{\circ} \mathrm{C}$, respectively [24-27]. The conventional super-elastic NiTi file has an austenite structure [24-29], whereas NiTi file with thermal processing are in the martensite condition at body temperature $[24,26,27,30]$. In addition, the critical stress for martensite reorientation of CM Wires is $128 \mathrm{MPa}-251 \mathrm{MPa}$ at room temperature and $37^{\circ} \mathrm{C}$, which is much lower than the critical stress for stress-induced martensite transformation of the super-elastic wires (490 MPa -582 MPa) [24]. However, the maximum strain of CM Wires before fracture (58.4\%-84.7\%) is much higher than that of the super-elastic wires (16.7\%-27.5\%). These results indicate the superior flexibility of CM Wire compared with conventional superelastic NiTi wire.

\section{R phase}

In 2008, SybronEndo developed a manufacturing process to create a NiTi endodontic instrument- Twisted Files (TFs). According to the manufacturer, TF instruments were developed by transforming a raw NiTi wire in the austenite phase into the R-phase through a thermal process. The aging of Ni-rich NiTi alloy at the proper temperature may cause the precipitation of the Ti3Ni4 phase, and thermomechanical treatment of NiTi alloy may create rearranged dislocation structures [31]. An instrument made from the R-phase wire would be more flexible [32].

R-phase is an intermediate phase with a rhombohedral structure that can form during forward transformation from martensite to austenite (B2-B19') on heating and reverse transformation from austenite to martensite (B19'-B2) on cooling. It exhibits the characteristics of thermoelastic martensitic transformation, i.e., shape memory and superelasticity effects, with a lower Young's modulus than austenite.

\section{Design features}

Along with other factors like material's properties and processing methods, design features are also a determining factor in instrument's operation technique and the range of objectives that could be solved by its use. Various design features of the instruments are described as follows

\section{Tip design}

Tip is an element of the working part of instrument that performs the guiding function. The tip might have a sharp or rounded (bulletlike) configuration, depending on whether it appears: active (cutting tip), or passive (non-cutting tip). Most of the current file systems have passive tips which does not have cutting edges and does not possess cutting properties. This reduces the risk of instrument deviation from the canal axis, and as a result the risk of transportation or ledge formation [33-35].

\section{Taper}

It is the ratio of the instrument diameters at two different points of the cutting part to the distance between them. Taper is expressed in fractional form or in percentage. The taper of traditional hand instruments according to the ISO standard is $0.02 \mathrm{~mm} / \mathrm{mm}$ or $2 \%$ [36]. This means that for every millimetre of the cutting part, the external instrument diameter increases by $0.02 \mathrm{~mm}$ from the tip towards the shank.

NiTi rotary files usually have an increased taper (4\%-12\%) or may have a constant (K3) or variable taper (ProTaper) along their length.

\section{Rake angle}

It is the angle formed by the cutting edge and a cross section taken perpendicular to the long axis of the instrument. The cutting angle, on the other hand, is the angle formed by the cutting edge and a radius when the file is sectioned perpendicular to the cutting edge. The rake angle determines the instrument-substrate interaction pattern. It may be negative, positive or neutral (equal to zero). In case of negative rake angle, cutting is not aggressive; the instrument scratches a surface rather than cuts. In case of a positive rake angle, cutting is very aggressive. Most conventional endodontic files utilize a negative or "substantially neutral" rake angle. An overly positive rake angle will result in digging and gouging of the dentin, which can lead to separation.

\section{Radial land}

It is a surface that projects axially from the central axis, between 
flutes, as far as the cutting edge. It is the combination of a non-cutting tip and radial land that keeps a file centered in the canal. Rotary files either have full radial lands or recessed lands. A full land effectively keeps the file centered, while a recessed land allows for a less frictional resistance. Land touches the canal walls at periphery of file and reduces the tendency of file to screw into the canal, transportation of canal, progression of microcracks on circumference, supports the cutting edge, and limits the depth of cut. However, radial lands on rotary files increases lateral resistance resulting in increased torque requirement elevating the danger for instrument fracture. Initially NiTi files incorporated this feature, but is not present in the contemporary NiTi instruments.

\section{Helical angle}

It is the angle that the cutting edge makes with the long axis of the file. Files with a constant helical flute angle allow debris to accumulate, particularly in the coronal part of the file. Additionally, files that maintain the same helical angle along the entire working length will be more susceptible to the effect of "screwing in" forces. By varying the flute angles, debris will be removed in a more efficient manner and the file will be less likely to screw into the canal.

\section{Pitch}

Pitch is the number of spirals or threads per unit length. The result of a constant pitch and constant helical angles is a "pulling down" or "sucking down into" the canal. This is particularly significant in rotary instrumentation when using files with a constant taper. A variable helical angle along with a variable pitch is preferred [37].

\section{Mechanical Classification of File Systems}

\section{First-generation files}

The first rotary 0.02 taper NiTi instrument (Dr. John McSpadden, 1992) had problems associated with file breakage. Later, ProFile 0.04 tapered series was introduced by Dr. Johnson in 1994 followed by ProFile 0.06 taper and the "Orifice Shapers." Other rotary file were the LightSpeed, the Quantec, and the Greater Taper files. First generation files had passive cutting radial lands, fixed tapers over the length of their working parts, required a considerable number of files to achieve preparation objectives, and had neutral or slightly negative rake angles [38].

\section{Second-generation files}

They possessed actively cutting edges without radial lands thus requiring fewer instruments to fully prepare a canal, and the angle between the cutting blade and the longitudinal axis of the instrument lower than in first-generation files, reducing the tendency for a screwing effect during use [38].

Several second generation systems had positive rake angles giving them greater cutting efficiency. NiTi files included are ProTaper rotary files, K3 system, Mtwo, Hero Shaper, EndoSequence, and BioRaCe.

\section{Third-generation files}

Improvements in NiTi metallurgy is the characteristic of third generation mechanical shaping files since 2007. Heat treatment (thermal processing) adjusts the transition temperatures of NiTi alloys [39-43] and affects the fatigue resistance of NiTi endodontic files. Third generation file included HyFlex CM, K3XF, ProFile GT Series X, ProFile Vortex and Vortex Blue, TYPHOON ${ }^{\text {sw }}$ Infinite Flex $\mathrm{NiTi}$, and Twisted Files.

Thermomechanical heat treatment in Hyflex CM files makes them more resistant to cyclic fatigue; reducing the incidence of file separation [38]. Hyflex EDM files are produced using Electrical Discharge Machining, resulting to be extremely flexible and fracture resistant. In cases of curved canals, Hyflex EDM is used along with Hyflex CM file (20/0.04). K3XF Files possess basic features of the original $\mathrm{K} 3$ files plus flexibility and resistance to cyclic fatigue owing to the proprietary R-phase technology. K3XF instruments have superior fatigue resistance compared with conventional superelastic NiTi instruments $[10,44,45]$.

\section{Fourth-generation files}

Reciprocation, defined as any repetitive backward and forward movement, is clinically utilized to drive stainless-steel files since 1958. Initially, all reciprocating motors and related handpieces rotated files in large equal angles of $90^{\circ}$ clockwise (CW) and counterclockwise (CCW) rotation. Over time, virtually all reciprocating systems began to utilize smaller, yet equal $30^{\circ}$ angles of CW/CCW rotation (M4, Endo-Eze AET and Endo-Exprss). However, current reciprocating systems are based on unequal CW/CCW angles (WaveOne and Reciproc).

WaveOne file, manufactured by M-wire technology, represents the design features of second and third generation files, along with a reciprocating motor that drives any given file at unequal bidirectional angles. The counter clockwise (CCW) engaging angle is $170^{\circ}$ while the clockwise (CW) disengaging angle is $50^{\circ}$ with an average speed of 350 $\mathrm{rpm}$, designed to be less than the elastic limit of the file. After three CCW and CW cutting cycles, the file rotates $360^{\circ}$, or one complete circle.

Reciproc files are thermally treated, single file system that are used at 10 cycles of reciprocation per second, the equivalent of approximately $300 \mathrm{rpm}$, with CW angle being $150^{\circ}$ and CCW angle being $30^{\circ}$.

The self-adjusting file (SAF) is designed as a cylinder of thinwalled, delicate NiTi lattice with a lightly abrasive surface, capable of adapting itself to the canal shape three-dimensionally [46]. The SAF system uses a hollow reciprocating instrument allowing for simultaneous irrigation throughout the mechanical preparation.

\section{Fifth-generation files}

The fifth generation of shaping files are designed such that the center of mass and/or the center of rotation are offset. In rotation, these files produce a mechanical wave of motion that travels along the active length of the file. This swaggering effect serves to minimize the engagement between the file and dentin compared to the action of a fixed tapered file with a centered mass of rotation [47]. Reduced engagement limits any undesirable taper lock, the screw effect, and the torque on any given file. An offset file design may also decrease the probability of laterally compacting the debris and blocking the root canal system anatomy. Examples of file systems include Revo-S, One Shape and ProTaper Next. ProTaper Next is the successor to the ProTaper Universal system. PTN files include various tapers on a 
single file, M-wire technology, and the offset design.

\section{Reciprocation vs. rotary}

Reciprocating motion is defined as a repeated backward and forward (CW/CCW) movement [48]. Variations of reciprocating motion include complete reciprocation (oscillation), partial reciprocation (rotational effect), and hybrid reciprocation (combined movements), that can be fixed or flexible (i.e., they can shift from one type of reciprocation to the other in the canal based on mechanical resistance and torque) [49]. Reciprocation can determine a dynamic of cutting that can resemble the action of the balanced force technique described by Roane, et al. in 1985 [50]. This contributes to maintain the instrument centered in the $\mathrm{RC}$, being the cutting force equal on the concave and convex side of the curve.

Plotino, et al. [51] in their literature review assessed the reciprocation and concluded that reciprocation motion seems advantageous that it reduces the incidence of instrument fracture i.e., it extends the life span of the NiTi files, can better preserve the original canal anatomy in curved root canals and reduces the shaping time compared with rotary full-sequence systems. Reciprocating files seem to cause fewer or an equivalent rate of dentinal microcracks compared with rotary full-sequence systems. Compared to rotary motion, reciprocation does not seem to reduce the cutting efficiency of the files. The cleaning effectiveness of reciprocating files appears comparable with rotary full-sequence systems. However, the ability of reciprocating files to extrude less debris than continuous rotating files is controversial.

\section{Glide path}

As defined by West, it is a smooth radicular tunnel from the orifice of the canal to the physiologic terminus of the root canal [52,53]. It is achieved when the file forming it can enter from the orifice and follow the smooth canal walls uninterrupted to the terminus [52,54], confirming that there is a pathway for rotary instruments to passively follow in the canal. Its minimal size should be a "super loose No. 10" endondontic file. Without a glide path, rotary files can easily screw themselves into canals by engaging more dentin and separate. The glide path assures that the tip of the file will not become locked as it moves apically and that the canal is free and clear of significant debris and blockage, which otherwise could cause iatrogenic error [55]. The lack of glide path establishment may result in ledge formation, blockage of root canals, transportation, zip formation, perforation and instrument fracture. Creating a .02 tapered glidepath is critical for the safe and effective use of nickel-titanium rotary shaping instruments. Glidepath can be described as a manual glide path created with handfiles, or a mechanical glide path created with rotary files [56].

Instruments to prepare glide-path can be manual including K-Files, C+ Files, Pathfinders ${ }^{\mathrm{TM}}$, S-finders, D-finders, or mechanical including PathFiles, G-files, Safesiders, V-files, EndoWave, Progliders.

\section{Clinical safety guidelines during NiTi instrumentation [57]}

Generally, following suggestions should be considered to avoid iatrogenic errors:

- Avoid subjecting NiTi rotary instruments to excessive stress.

- Use instruments that are less prone to fracture.
- Follow an instrument use protocol.

- Assess root canal curvatures radiographically and instrument them carefully.

- Ensure that the endodontic access preparation is adequate.

- Make a glide path with small size files (sizes 10-20). This allows preservation of pathway to the working length and reduces the formation of transportations and ledges.

- Use crown down approach.

- Recapitulate using a small file to establish and maintain patency to reduce transportation and respecting the original canal shapes.

- No instrument should be introduced into the root canal space until an appropriate irrigant is introduced into the pulp chamber.

- Do not stop the preparation in between. Overzealous use of NiTi rotary files (especially beyond apical foramen) could cause cracks in apical roots.

\section{Failures in NiTi Endodontic Instruments}

\section{Torsional failure}

Torsion is one of the primary mechanisms responsible for the intracanal separation of NiTi endodontic instruments [58,59]. It can be generated within the rotary file when the tip or some part of the instrument is locked against the canal wall while the shank of the file continues to rotate or is subjected to excessive pressure by the clinician $[3,60]$. The tip fractures when the handpiece torque exceeds the ultimate strength of the metal [61]. High torsional stiffness is desirable for the clinical performance of rotary files owing to the enhanced cutting efficiency and reduced torsional failure risk [62-64].

\section{Flexural failure}

Cyclic fatigue occurs when a metal is subjected to repeated cycles of tension and compression that cause its structure to break down, ultimately leading to fracture. It is the main reason for the majority (93\%) of broken instruments. The fracture caused by cyclic fatigue of NiTi endodontic instruments is difficult to detect during clinical practice due to the invisible signs of permanent deformation during cyclic fatigue [65]. Thus attempts have been made to improve the resistance to cyclic fatigue for NiTi instruments, including thermomechanical processing and exploring new materials. M-wire instruments demonstrate superior resistance to fatigue-crack initiation and propagation compared with regular super elastic files, owing to a better reorientation capability of the $\mathrm{M}$ variants [66].

\section{Concluding remarks}

From a material point of view, the properties of NiTi alloys depend on their chemical composition, phase constitution and fabrication procedures. Flexibility is beneficial for maintaining the original shape of root canals, especially severe curvatures. Adequate torsional resistance and flexural fatigue resistance favour reducing the occurrence of the intracanal separation. Thus, flexibility and resistance to fracture constitute properties expected for an ideal root canal file $[62,67]$. Endodontic world is seeing a revolutionary change with continuously evolving NiTi files. Advantageously, 
$\mathrm{NiTi}$ rotary shaping files have nearly eliminated the iatrogenic instrumentation complications associated with endodontic steel instruments. As an increasing number of new NiTi files are being introduced in the market at a very fast pace, it becomes imperative for the clinicians to understand the changes in their design features, impact of thermomechanical heat treatments and kinematics on the performance of those contemporary NiTi systems, so that one can make a judicious choice based on case difficulty and the teeth that have been endodontically treated last longer in the mouth.

\section{References}

1. Walia HM, Bratley WA, Gerstein H. An initial investigation of the bending and tortional properties of Nitinol root canal files. J Endod. 1988; 14: 346-351.

2. Thomson SA. An overview of nickel-titanium alloys used in dentistry. Int Endod J. 2000; 33: 297-310.

3. Arab-Chirani R, Chevalier V, Arab-Chirani S, Calloch S. Comparative analysis of torsional and bending behaviour through finite-element models of 5 NiTi endodontic instruments. Oral Surg Oral Med Oral Pathol Oral Radiol Endod. 2011; 111: 115-121.

4. Hülsmann M, Peters OA, Dummer PMH. Mechanical preparation of roo canals: shaping goals, techniques and means. Endod Topics. 2005; 10: $30-$ 76.

5. Diemer $F$, Calas $P$. Effect of pitch length on the behavior of rotary triple helix root canal instruments. J Endod. 2004; 30: 716-718.

6. Peters OA, Gluskin AK, Weiss RA, Han JT. An in vitro assessment of the physical properties of novel Hyflex nickel-titanium rotary instruments. In Endod J. 2012; 45: 1027-1034.

7. Testarelli L, Plotino G, Al-Sudani D, Vincenzi V, Giansiracusa A, Grande NM Gambarini G. Bending properties of a new nickel-titanium alloy with a lower percent by weight of nickel. J Endod. 2011; 37: 1293-1295

8. Shen Y, Qian W, Abtin H, Gao Y, Haapasalo M. Fatigue testing of controlled memory wire nickel-titanium rotary instruments. J Endod. 2011; 37: 997 1001.

9. Ye J, Gao Y. Metallurgical characterization of M-wire nickel-titanium shape memory alloy used for endodontic rotary instruments during low-cycle fatigue. J Endod. 2012; 38: 105-107.

10. Gambarini G, Plotino G, Grande NM, Al-Sudani D, De Luca M, Testarelli L. Mechanical properties of nickel-titanium rotary instruments produced with a new manufacturing technique. Int Endod J. 2011; 44: 337-341.

11. Zhou H, Peng B, Zheng YF. An overview of the mechanical properties of nickel-titanium endodontic instruments. Endod Topics. 2013; 29: 42-54.

12. Liu Y, McCormick PG. Thermodynamic analysis of the martensitic transformation in NiTi-II: effect of transformation cycling. Acta Mater. 1994; 7: $2407-2413$.

13. Frick C, Ortega A, Tyber J, A.El.M.Maksound, Maier HJ, Liu Y, et al. Therma processing of polycrystalline NiTi shape memory alloys. Mater Sci Eng A 2005; 405: 34-49.

14. Gutmann JL, Gao Y. Alteration in the inherent metallic and surface properties of nickel-titanium root canal instruments to enhance performance, durability and safety: a focused review. Int Endod J. 2012; 45: 113-28.

15. Otsuka K, Ren X. Physical metallurgy of Ti-Ni based shape memory alloys Prog Mater Sci. 2005; 50: 511-678.

16. Brantley WA. Orthodontic wires. In: Brantley WA, Eliades T, eds. Orthodontic Materials: Scientific and Clinical Aspects, 52-6. Stuttgart: Thieme. 2001: 77103.

17. Zadno R, Duerig TW. Linear superelasticity in cold worked NiTi. In: Duerig TW, Melton KN, Stockel D, Wayman CM, eds. Engineering Aspects of Shape Memory Alloys. London: Butterworth-Heinemann, 1990: 414.

18. Bidaux JE, Bataillard L, Manson JA, Gotthardt R. Phase transformation behavior of thin shape memory alloy wires embedded in a polymer matrix composite. Proc 3rd Eur Conf on Advanced Materials and Processes 1993: 1-5.

19. Hodson DE, Wu MH, Biermann RJ. Shape memory alloys. In: Metals Handbook, 10th edn. ASM International, 1990; 2: 897-902.

20. Davis JR. ASM Specialty Handbook: Nickel, Cobalt, and Their Alloys. Materials? Park, OH: ASM International; 2000.

21. Berendt CJ, Yang J. Endodontic instruments with improved fatigue resistance. In: Berg B, Mitchell MR, Proft J, eds. International Conference on Shape Memory and Superelastic Technologies. Pacific Grove, CA: ASM International; 2006

22. Johnson E, Lloyd A, Kuttler S, Namerow K. Comparison between a nove nickel-titanium alloy and 508 nitinol on the cyclic fatigue life of ProFile 25/.04 rotary instruments. J Endod. 2008; 34: 1406-1409.

23. CM Wire press release. Johnson City, TN: DS Dental; 2010

24. Zhou H, Shen Y, Zheng W, Li L, Zheng YF, Haapasalo M. The mechanical properties of controlled memory and superelastic NiTi wires used in the manufacture of rotary endodontic instruments. J Endod. 2012; 38: 1535-1540.

25. Hou XM, Yahata Y, Hayashi Y, Ebihara A, Hanawa T, Suda H. Phase transformation behaviour and bending property of twisted nickel-titanium endodontic instruments. Int Endod J. 2011; 44: 253-258.

26. Shen Y, Zhou HM, Zheng YF, Campbell L, Peng B, Haapasalo M. Metallurgical characterization of controlled memory wire nickel-titanium rotary instruments. J Endod. 2011; 37: 1566-1571.

27. Ye J, Gao Y. Metallurgical characterization of M-Wire nickel-titanium shape memory alloy used for endodontic rotary instruments during low-cycle fatigue. J Endod. 2012; 38: 105-107

28. Brantley WA, Svec TA, lijima M, Powers JM, Grentzer TH. Differential scanning calorimetric studies of nickel-titanium rotary endodontic instruments. J Endod. 2002; 28: 567-72.

29. Brantley WA, Svec TA, lijima M, Powers JM, Grentzer TH. Differential scanning calorimetric studies of nickel-titanium rotary endodontic instruments after simulated clinical use. J Endod. 2002; 28: 774-778.

30. Alapati SB, Brantley WA, lijima M, Clark WA, Kovarik L, Buie C, et al. Metallurgical characterization of a new nickel-titanium wire for rotary endodontic instruments. J Endod. 2009; 35: 1589-1593.

31. Otsuka K, Ren X. Physical metallurgy of Ti-Ni based shape memory alloys. Prog Mater Sci. 2005; 50: 511-678.

32. Cheung GS, Shen Y, Darvell BW. Does electropolishing improve the low cycle fatigue behavior of a nickel-titanium rotary instrument in hypochlorite? J Endod. 2007; 33: 1217-1221.

33. Sabala CL, Roane JB, Southard LZ. Instrumentation of curved canals using a modified tipped instrument: a comparison study. J Endod. 1988; 14: 59-64.

34. Powell SE, Wong PD, Simon JH. A comparison of the effect of modified and nonmodified instrument tips on apical canal configuration. Part II. J Endod. 1988; $14: 224-228$

35. Kosa DA, Marshall G, Baumgartner JC. An analysis of canal centering using mechanical instrumentation techniques. J Endod. 1999; 25: 441-445.

36. ISO 3630-1. Dentistry-Root canal instruments-Part 1: General requirements and test methods, ed 2. Switzerland: International Organization for Standardization, 2008.

37. Young GR, Parashos $\mathrm{P}$, Messer $\mathrm{HH}$. The principles of techniques for cleaning root canals. Aust Dent J. 2007; 52: 52-60.

38. Haapasalo M, Shen Y. Evolution of nickel-titanium instruments: from past to future. Endod Topics. 2013; 29: 3-17.

39. Liu Y, McCormick PG. Thermodynamic analysis of the martensitic transformation in NiTi-II. Effect of transformation cycling. Acta Metall Mater. 1994; $7: 2407-2413$.

40. Frick C, Ortega A, Tyber J, Maksound A, Maier H, Liu Y, et al. Thermal 
processing of polycrystalline NiTi shape memory alloys. Mater Sci Eng: A 2005; 405: 34-49.

41. Gutmann JL, Gao Y. Alteration in the inherent metallic and surface properties of nickel-titanium root canal instruments to enhance performance, durability and safety: a focused review. Int Endod J. 2012; 45: 113-128.

42. Shen Y, Zhou HM, Zheng YF, Peng B, Haapasalo M. Current challenges and concepts of the thermomechanical treatment of nickel-titanium instruments. J Endod. 2013; 39: 163-172.

43. CM Wire press release. Johnson City, TN: DS Dental, 2010.

44. Shen Y, Zhou HM, Wang Z, Campbell L, Zheng YF, Haapasalo M. Phase transformation behavior and mechanical properties of thermomechanically treated K3XF nickel-titanium instruments. J Endod 2013; 39: 919-923.

45. Plotino G, Costanzo A, Grande NM, Petrovic R, Testarelli L, Gambarini G Experimental evaluation on the influence of autoclave sterilization on the cyclic fatigue of new nickel-titanium rotary instruments. J Endod. 2012; 38: $222-225$

46. Metzger Z, Teperovich E, Cohen R, Zary R, Paqué F, Hülsmann M. The selfadjusting file (SAF). Part 3: removal of debris and smear layer-a scanning electron microscope study. J Endod. 2010; 36: 697-702.

47. Hashem AA, Ghoneim AG, Lutfy RA, Foda MY, Omar GA. Geometric analysis of root canals prepared by four rotary NiTi shaping systems. J Endod. 2012; 38: $996-1000$.

48. The Oxford English Dictionary. Oxford, UK: Clarendon Press; 1989.

49. Grande NM, Ahmed HM, Cohen S, Bukiet F, Plotino G. Current Assessment of Reciprocation in Endodontic Preparation: A Comprehensive Review-Part I: Historic Perspectives and Current Applications. J Endod. 2015; 41: 17781783.

50. Roane JB, Sabala CL, Duncanson MG Jr. The "balanced force" concept for instrumentation of curved canals. J Endod. 1985; 11: 203-211.

51. Plotino G, Ahmed HM, Grande NM, Cohen S, Bukiet F. Current assessment of reciprocation in endodontic preparation: a comprehensive review-part II: properties and effectiveness. J Endo. 2015; 41: 1939-1950.

52. van der Vyver P. Creating a glide path for rotary NiTi instruments: part one. Endod Prac. 2011: 40-43

53. West JD. The endodontic Glidepath: "Secret to rotary safety". Dent Today 2010; 29: 86, 88, 90-93.
54. West J. Endodontic update 2006. J Esthet Restor Dent. 2006; 18: 280-300.

55. Richard Mounce. An excellent glide path, the road to smoother endodontics. Oral health journal. 2004; 94, part 3: 51-68

56. Chris J. Lampert. The Secret of Rotary Glide Path with Pre Shapers. Specialized Endo Endodontic Education Series.

57. Di Fiore PM. A dozen ways to prevent nickel-titanium rotary instrument fracture. J Am Dent Assoc. 2007; 138: 196-201.

58. Alapati SB, Brantley WA, Svec TA, Powers JM, Nusstein JM, Daehn GS. SEM observations of nickel- titanium rotary endodontic instruments that fractured during clinical use. J Endod. 2005; 31: 40-43.

59. Sattapan B, Palamara JE, Messer HH. Torque during canal instrumentation using rotary nickel-titanium files. J Endod. 2000; 26: 156-160.

60. Chevalier V, Arbab-Chirani R, Arbab-Chirani S, Calloch S. An improved model of 3-dimensional finite element analysis of mechanical behavior of endodontic instruments. Oral Surg Oral Med Oral Pathol Oral Radiol Endod. 2010; 109: 111-121.

61. Martín B, Zelada G, Varela P, Bahillo JG, Magán F, Ahn S, et al. Factors influencing the fracture of nickel-titanium rotary instruments. Int Endod J. 2003; 36: 262-266.

62. Schäfer E, Dzepina A, Danesh G. Bending properties of rotary nickel-titanium instruments. Oral Surg Oral Med Oral Pathol Oral Radiol Endod. 2003; 96: 757-763.

63. Yum J, Cheung GS, Park JK, Hur B, Kim HC. Torsional strength and toughness of nickel-titanium rotary files. J Endod. 2011; 37: 382-386.

64. Berutti E, Chiandussi G, Gaviglio I, Ibba A. Comparative analysis of torsional and bending stresses in two mathematical models of nickel-titanium rotary instruments: ProTaper versus ProFile. J Endod. 2003; 29: 15-19.

65. Sattapan B, Nervo GJ, Palamara JE, Messer HH. Defects in rotary nickeltitanium files after clinical use. J Endod. 2000; 26: 161-165.

66. Gao Y, Shotton V, Wilkinson K, Phillips G, Johnson WB. Effects of raw material and rotational speed on the cyclic fatigue of ProFile Vortex rotary instruments. J Endod. 2010; 36: 1205-1209.

67. Yared G, Kulkarni GK, Ghossayn F. An in vitro study of the torsional properties of new and used K3 instruments. Int Endod J. 2003; 36: 764-769.
Austin J Dent - Volume 5 Issue 4 - 2018

ISSN : 2381-9189 | www.austinpublishing group.com

Nagpal et al. () All rights are reserved
Citation: Agarwal S, Nagpal R and Singh UP. NiTi Endodontics: Contemporary Views Reviewed. Austin J Dent. 2018; 5(4): 1112 